\title{
Regulation of tNOX expression through the ROS-p53-POU3F2 axis contributes to cellular responses against oxaliplatin in human colon cancer cells
}

Huei-Yu Chen', Atikul Islam', Tien-Ming Yuan², Shi-Wen Chen², Pei-Fen Liu ${ }^{3}$ and Pin Ju Chueh ${ }^{1,4,5,6^{*}}$ (1)

\begin{abstract}
Background: Oxaliplatin belongs to the platinum-based drug family and has shown promise in treating cancer by binding to DNA to induce cytotoxicity. However, individual patients show diverse therapeutic responses toward oxaliplatin due to yet-unknown underlying mechanisms. We recently established that oxaliplatin also exert its anticancer activity in gastric cancer cell lines by targeting tumor-associated NADH oxidase (tNOX), attenuate NAD ${ }^{+}$ generation and reduce $\mathrm{NAD}^{+}$-dependent sirtuin 1 (SIRT1) deacetylase activity, which in turn enhances p53 acetylation and apoptosis.
\end{abstract}

Methods: In this study, differential cellular outcomes in response to oxaliplatin exposure of p53-wild-type versus p53-null HCT116 human colon cancer cells were examined. Cell growth profile was determined by cell impedance measurements and apoptosis was analyzed by flow cytometry. The engagement between oxaliplatin and tNOX protein was studied by cellular thermal shift assay. Furthermore, western blot analysis revealed that p53 was important in regulating tNOX expression in these cell lines.

Results: In p53-wild-type cells, we found that oxaliplatin inhibited cell growth by inducing apoptosis and concurrently down-regulating tNOX at both the transcriptional and translational levels. In p53-null cells, in contrast, oxaliplatin moderately up-regulated tNOX expression and yielded no apoptosis and much less cytotoxicity. Further experiments revealed that in p53-wild-type cells, oxaliplatin enhanced ROS generation and p53 transcriptional activation, leading to down-regulation of the transcriptional factor, POU3F2, which enhances the expression of tNOX. Moreover, the addition of a ROS scavenger reversed the p53 activation, POU3F2 down-regulation, and apoptosis induced by oxaliplatin in p53-wild-type cells. In the p53-null line, on the other hand, oxaliplatin treatment triggered less ROS generation and no p53 protein, such that POU3F2 and tNOX were not down-regulated and oxaliplatin-mediated cytotoxicity was attenuated.

Conclusion: Our results show that oxaliplatin mediates differential cellular responses in colon cancer cells depending on their p53 status, and demonstrate that the ROS-p53 axis is important for regulating POU3F2 and its downstream target, tNOX. Notably, the depletion of tNOX sensitizes p53-null cells to both spontaneous and oxaliplatin-induced apoptosis. Our work thus clearly shows a scenario in which targeting of tNOX may be a potential strategy for cancer therapy in a p53-inactivated system.

Keywords: Apoptosis, Oxaliplatin, p53, Tumor-associated NADH oxidase (tNOX or ENOX2), Sirtuin 1 (SIRT1), ROS

\footnotetext{
* Correspondence: pjchueh@dragon.nchu.edu.tw

'Institute of Biomedical Sciences, National Chung Hsing University, Taichung

40227, Taiwan

${ }^{4}$ Graduate Institute of Basic Medicine, China Medical University, Taichung

40402, Taiwan

Full list of author information is available at the end of the article
}

(c) The Author(s). 2018 Open Access This article is distributed under the terms of the Creative Commons Attribution 4.0 International License (http://creativecommons.org/licenses/by/4.0/), which permits unrestricted use, distribution, and reproduction in any medium, provided you give appropriate credit to the original author(s) and the source, provide a link to the Creative Commons license, and indicate if changes were made. The Creative Commons Public Domain Dedication waiver (http://creativecommons.org/publicdomain/zero/1.0/) applies to the data made available in this article, unless otherwise stated. 


\section{Background}

The newest numbers indicate that colorectal cancer (CRC) remains the third most commonly diagnosed cancer, and 50,260 deaths from this disease were predicted in the United States for 2017 [1]. Despite extensive efforts to identify a better therapeutic strategy, chemotherapeutic drugs continue to be widely used to treat CRC, especially at its advanced stages. The utilized drugs include, oxaliplatin, which belongs to the third generation of platinum-based compounds; these drugs bind and form DNA adducts that interfere with DNA replication to initiate DNA damage and apoptosis [2, 3]. Unfortunately, the anti-cancer efficacy of oxaliplatin often hindered by tumor-related resistance, which is frequently associated with changes in cellular detoxification and transportation, DNA damage and repair, and cell death [4]. Thus, it is not surprising that p53, which is a functional tumor suppressor that plays paramount roles in regulating cell cycle progression, DNA repair, and apoptosis, is associated with the susceptibility of tumors to oxaliplatin-based therapy [5-8]. p53 is inactive or mutated in many CRC patients; this leads to an acquired resistance that considerably limits the effectiveness of therapeutic drugs for cancer management. To address this, researchers are seeking to identify and further target additional factors that contribute to drug resistance in the hopes of designing new therapeutic strategies.

We recently examined the effects of oxaliplatin in three gastric cancer cell lines that differed in their p53 status, and found that oxaliplatin-mediated cytotoxicity and apoptosis induction were very dissimilar among them [9]. Interestingly, the responsiveness toward oxaliplatin in these cell lines corresponded to both their p53 functionality and the expression level of tumor-associated $\mathrm{NADH}$ oxidase (tNOX) [9]. tNOX catalyzes the conversion of reduced NADH to oxidized $\mathrm{NAD}^{+}$; it universally expressed in a wide range of transformed/cancerous lines and is positively correlated with cell growth ability [10-13]. Numerous anticancer drugs (oxaliplatin, capsaicin, doxorubicin and its derivatives, etc.) have been shown to trigger tNOX down-regulation and concurrent apoptosis [9, 14-18]. Our recent work showed that oxaliplatin diminishes the ratio between tNOX-catalyzed intracellular $\mathrm{NAD}^{+}$and $\mathrm{NADH}$, and thereby lessens $\mathrm{NAD}^{+}$-dependent SIRT1 deacetylase activity, resulting in p53 acetylation and apoptosis induction in p53-wild-type gastric cancer cells. Conversely, oxaliplatin had much smaller inhibitory effects on tNOX activity/expression and triggered little apoptosis in p53-mutated cells [9]. Furthermore, forced depletion of tNOX by RNA interference in these resistant p53-mutated cells augmented their spontaneous apoptosis, increased their drug sensitivity, and diminished their cell growth [9]. These findings and those of other studies strongly support the notion that $\mathrm{tNOX}$ may be a potential therapeutic drug target $[14,15,18-21]$. However, it was unclear whether p53 participates in governing anticancer-drug-induced inhibition of tNOX and subsequent apoptosis of cancer cells.

Here, we focused on the p53 status and regulation of tNOX expression in HCT116 human colon cancer p53-wild-type and -null cells and sought to decipher the molecular basis underlying their differential cellular responses to oxaliplatin. We found that oxaliplatin mediated very different outcomes in these cells depending on their p53 functionality, ranging from increasing stress tolerance to apoptosis induction, and that these effects were associated with distinct transcriptional and translational regulations of $\mathrm{tNOX}$.

\section{Methods \\ Materials}

Fetal bovine serum (FBS) and penicillin/streptomycin were obtained from Gibco/BRL Life Technologies (Grand Island, NY, USA). The anti-Bak, anti-Bax, anti-Bcl-2, anti-PARP, anti-p53, anti-phospho-p53, anti-acetyl-p53, and anti-SIRT1 antibodies were purchased from Cell Signaling Technology, Inc. (Beverly, MA, USA). The anti-survivin antibody was purchased from Santa Cruz Biotechnology, Inc. (Santa Cruz, CA, USA). The anti-POU3F2 antibody was from GeneTex, Inc. (Irvine, CA, USA). The anti- $\beta$-actin antibody was from Millipore Corp. (Temecula, CA, USA). The antisera to tNOX used in Western blot analyses were generated as described previously [22]. The anti-mouse and anti-rabbit IgG antibodies and other chemicals were purchased from Sigma Chemical Company (St. Louis, MO, USA) unless otherwise specified.

\section{Cell culture and transfection}

HCT116 (human colorectal cancer) wild-type (The Bioresource Collection and Research Center, BCRC, Hsinchu, Taiwan) and $\mathrm{p} 53^{-/-}$(from Horizon Discovery, Cambridge, UK) cells were grown in McCoy's 5A medium. AGS (gastric adenocarcinoma, p53 wild-type) and TMK-1 (from a poorly differentiated adenocarcinoma, mutant p53) human stomach cancer cells, which were grown in RPMI-1640, were kindly provided by Dr. Chun-Ying Wu (Department of Gastroenterology, Taichung Veterans General Hospital, Taiwan). SAS (tongue squamous carcinoma, p53 functional) and HSC-3 (oral squamous carcinoma, p53 inactive) cells, which were grown in DMEM, were kindly provided by Dr. Yuen-Chun Li (Department of Biomedical Sciences, Chung Shan Medical University, Taiwan). All media were supplemented with $10 \%$ fetal bovine serum, 100 units $/ \mathrm{mL}$ penicillin and $50 \mu \mathrm{g} / \mathrm{mL}$ streptomycin. The cells were grown at $37^{\circ} \mathrm{C}$ in a humidified atmosphere of $5 \% \mathrm{CO}_{2}$ in air, with replacement of the medium every 2-3 days. The experimental groups were 
treated with different concentrations of oxaliplatin dissolved in $\mathrm{ddH}_{2} \mathrm{O}$, and the controls were treated with the same volume of $\mathrm{ddH}_{2} \mathrm{O}$.

ON-TARGETplus tNOX (ENOX2) siRNA and negative control siRNA were purchased from Thermo Scientific, Inc. (Grand Island, NY) and the POU3F2-specific and negative control RNAi were constructed at the RNAi core facility of Academic Sinica (Taipei, Taiwan, ROC). Briefly, cells were seeded in 10-cm dishes, allowed to attach overnight, and then transfected with tNOX/POU3F2 siRNA or control siRNA using the Lipofectamin RNAiMAX Reagent (Gibco/BRL Life Technologies) according to the manufacturer's instructions.

\section{Plasmid constructs and luciferase assay}

The full protein-encoding sequence of the POU $3 F 2$ gene was amplified from human cDNA and the generated PCR products were cloned into the pCDNA3.1/Myc_His $(+) \mathrm{A}$ vector, and the obtained construct was used for POU3F2 overexpression experiments.

Fourteen-hundred base pairs of the 5'-flanking DNA sequence of the $t N O X$ gene were PCR amplified from the genomic DNA of HCT116 cells. The PCR products were subcloned into the pGL3-Basic luciferase reporter vector (Promega, Madison, WI, USA) to generate the pGL-1.4 kb construct for reporter assays. The reporter vectors plus the POU3F2 expression plasmid or empty vector were co-transfected into HCT116 p53 wild type cells using Lipofectamine 2000 (Promega) according to the manufacturer's instructions. Cells were harvested $48 \mathrm{~h}$ after transfection, and luciferase activity was measured using the Dual-Luciferase Reporter Assay System (Promega) according to the manufacturer's instructions.

\section{Continuous monitoring of cell impedance}

For continuous monitoring of changes in cell growth, cells $\left(7.5 \times 10^{3}\right.$ cells/well $)$ were seeded onto E-plates and incubated for $30 \mathrm{~min}$ at room temperature. The E-plates were placed onto a Real-Time Cell Analysis (RTCA) station (Roche, Germany) and the cells were grown overnight before being exposed to oxaliplatin or $\mathrm{ddH}_{2} \mathrm{O}$. Cell impedance was measured every hour for a total of $72 \mathrm{~h}$, as previously described [23], and was defined by the cell index $(\mathrm{CI})=\left(\mathrm{Z}_{\mathrm{i}}-\mathrm{Z}_{0}\right)[\mathrm{Ohm}] / 15[\mathrm{Ohm}]$, where $\mathrm{Z}_{0}$ is the background resistance and $Z_{i}$ is the resistance at an individual time point. A normalized $\mathrm{CI}$ was determined as the $\mathrm{CI}$ at a certain time point $\left(\mathrm{CI}_{\mathrm{ti}}\right)$ divided by that at the normalization time point $\left(\mathrm{CI}_{\mathrm{nml} \text { time }}\right)$.

\section{Apoptosis determination}

Apoptosis was measured using an Annexin V-FITC apoptosis detection kit (BD Pharmingen, San Jose, CA, USA). Cells cultured in 6-cm dishes were trypsinized, collected by centrifugation, washed, resuspended in $1 \times$ binding buffer, and stained with Annexin V-FITC, as recommended by the manufacturer. Cells were also stained with propidium iodide (PI) to detect necrosis or late apoptosis. The distributions of viable (FITC/PI double-negative), early apoptotic (FITC-positive), late apoptotic (FITC/PI double-positive), and necrotic (PI-positive/FITC-negative) cells were analyzed using a FC500 flow cytometer (Beckman Coulter, Inc. Indianapolis, IN). The results are expressed as a percentage of total cells.

\section{Cellular thermal shift assay (CETSA)}

Engagement between oxaliplatin and tNOX in cells was analyzed by CETSA. Samples were prepared from control cells and those exposed to the drug. For each set, $2 \times 10^{7}$ cells were seeded in a 10-cm cultured dish. After $24 \mathrm{~h}$ of culture, the cells were pretreated with $10 \mu \mathrm{M}$ MG132 for $1 \mathrm{~h}$, washed with PBS, treated with trypsin, and collected. Samples were centrifuged at 12,000 rpm for $2 \mathrm{~min}$ at room temperature, the pellets were gently resuspended with $1 \mathrm{~mL}$ of $\mathrm{PBS}$, and the samples were centrifuged at $7500 \mathrm{rpm}$ for $3 \mathrm{~min}$ at room temperature. The pellets were resuspended with $1 \mathrm{~mL}$ of PBS containing $20 \mathrm{mM}$ Tris- $\mathrm{HCl} \mathrm{pH} \mathrm{7.4,} 100 \mathrm{mM} \mathrm{NaCl}, 5 \mathrm{mM}$ EDTA, $2 \mathrm{mM}$ phenylmethylsulfonyl fluoride (PMSF), $10 \mathrm{ng} / \mathrm{ml}$ leupeptin, and $10 \mu \mathrm{g} / \mathrm{ml}$ aprotinin. The samples were transferred to Eppendorf tubes, subjected to three freeze-thaw cycles; for each cycle, they were exposed to liquid nitrogen for $3 \mathrm{~min}$, placed in a heating block at $25{ }^{\circ} \mathrm{C}$ for $3 \mathrm{~min}$, and vortexed briefly. The samples were then centrifuged at $12,000 \mathrm{rpm}$ for $30 \mathrm{~min}$ at $4{ }^{\circ} \mathrm{C}$, and the supernatants were transferred to new Eppendorf tubes. For the experimental sample set, oxaliplatin was added to a final concentration of $100 \mu \mathrm{M}$; for the control sample set, the same volume of vesicle solvent was added. The samples were heated at $37{ }^{\circ} \mathrm{C}$ for $1 \mathrm{~h}$ and dispensed to $100 \mu \mathrm{l}$ aliquots. Pairs consisting of one control aliquot and one from experimental aliquots were heated at $40{ }^{\circ} \mathrm{C}, 43{ }^{\circ} \mathrm{C}, 46{ }^{\circ} \mathrm{C}, 49^{\circ} \mathrm{C}, 52{ }^{\circ} \mathrm{C}, 55{ }^{\circ} \mathrm{C}, 58{ }^{\circ} \mathrm{C}$, $61{ }^{\circ} \mathrm{C}$, or $67{ }^{\circ} \mathrm{C}$ for $3 \mathrm{~min}$. Finally, the samples were placed on ice and subjected to Western blot analysis using antisera to tNOX [22].

\section{Measurement of the intracellular $\mathrm{NAD}^{+} / \mathrm{NADH}$ ratio}

The oxidized and reduced forms of intracellular NAD were determined using an NADH/NAD Quantification Kit (BioVision Inc. Milpitas, CA, USA), as described by the manufacturer. Briefly, $2 \times 10^{5}$ cells were washed with cold PBS, pelleted, and extracted by two freeze/thaw cycles with $400 \mu \mathrm{l}$ of $\mathrm{NADH} / \mathrm{NAD}^{+}$extraction buffer. The samples were vortexed and centrifuged at 14,000 rpm for $5 \mathrm{~min}$. The extracted $\mathrm{NADH} / \mathrm{NAD}^{+}$supernatant $(200 \mu \mathrm{l})$ was transferred to a microcentrifuge tube, heated to $60{ }^{\circ} \mathrm{C}$ for $30 \mathrm{~min}$ (to decompose $\mathrm{NAD}^{+}$but not $\mathrm{NADH})$, and then placed on ice. The samples were then 
centrifuged and transferred to a multiwell-plate. Standards and a $\mathrm{NAD}^{+}$cycling mix were prepared according to the manufacturer's protocol. The reaction mix $(100 \mu \mathrm{l})$ was distributed to each well containing NADH standards and samples, and the plates were incubated at room temperature for $5 \mathrm{~min}$ to convert $\mathrm{NAD}^{+}$to $\mathrm{NADH}$. The provided NADH developer solution was added to each well, and plates were incubated at room temperature for 15 or $30 \mathrm{~min}$. The reaction was stopped with $10 \mu \mathrm{l}$ of stop solution per well, and absorbance was measured at $450 \mathrm{~nm}$.

Reverse transcriptase-polymerase chain reaction (RT-PCR) Total RNA from gastric cancer cells was isolated using the TRIzol reagent (Gibco, Carlsbad, CA, USA). First strand cDNA was synthesized from $1 \mu \mathrm{g}$ of total RNA using Superscript II (Life Technologies, Rockville, MD, USA). The following primers sets were used for PCR amplifications: tNOX, 5'-GAAGTGTGATGCCGATAAC AG -3" (sense) and 5'-AGTACTAGAGCCCAGGCGA A-3' (antisense); POU3F2, 5'-TGGGATTTACCCAAGC GGAC -3" (sense) and 5'-TGTGGTGGAGTGTCCCT ACT-3' (antisense); and $\beta$-actin, 5'-ACTCACCTTGGTG GTGCATA-3' (sense) and 5'-ACACCTTGATGGGAAA GGTGG-3' (antisense). The reaction conditions consisted of 30 cycles of $95{ }^{\circ} \mathrm{C}$ for $30 \mathrm{~s}, 55^{\circ} \mathrm{C}$ for $30 \mathrm{~s}$, and $72{ }^{\circ} \mathrm{C}$ for $1 \mathrm{~min}$, followed by a final extension of $5 \mathrm{~min}$ at $72{ }^{\circ} \mathrm{C}$. The obtained PCR products were resolved by $1.4 \%$ agarose gels electrophoresis and visualized by ethidium bromide staining.

\section{Measurement of reactive oxygen species (ROS)}

Oxidative stress was determined by measuring the level of hydrogen peroxide $\left(\mathrm{H}_{2} \mathrm{O}_{2}\right)$ generated in the cells, as assessed by 5 -(6)-carboxy-2', $7^{\prime}$-dichlorodihydrofluorescein diacetate (carboxy- $\mathrm{H}_{2}$ DCFDA) staining. The nonpolar, nonionic $\mathrm{H}_{2}$-DCFDA is cell permeable and is hydrolyzed to nonfluorescent $\mathrm{H}_{2}$-DCF by intracellular esterases. In the presence of peroxide, $\mathrm{H}_{2}$-DCF is rapidly oxidized to highly fluorescent DCF. In brief, at the end of oxaliplatin treatment, cells $\left(2 \times 10^{5}\right)$ were washed

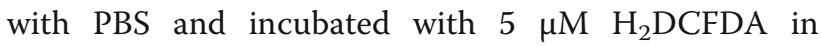
DMSO for $30 \mathrm{~min}$. The cells were then collected by trypsinization and centrifugation, washed with PBS, centrifuged at $200 \times \mathrm{g}$ for $5 \mathrm{~min}$ and analyzed immediately using a Beckman Coulter FC500 flow cytometer.

\section{Western blot analysis}

Cell extracts were prepared in lysis buffer containing $20 \mathrm{mM}$ Tris- $\mathrm{HCl} \mathrm{pH}$ 7.4, $100 \mathrm{mM} \mathrm{NaCl}, 5 \mathrm{mM}$ EDTA, $2 \mathrm{mM}$ PMSF, $10 \mathrm{ng} / \mathrm{ml}$ leupeptin, and $10 \mu \mathrm{g} / \mathrm{ml}$ aprotinin. Equal amounts of extracted proteins $(40 \mu \mathrm{g})$ were resolved by SDS-PAGE and transferred to nitrocellulose membranes (Schleicher \& Schuell, Keene, NH, USA).
The membranes were blocked with nonfat milk solution for $1 \mathrm{~h}$, and then washed and probed with the appropriate primary antibody. The membranes were rinsed with Tris-buffered saline containing $0.1 \%$ Tween 20 , incubated with horseradish peroxidase-conjugated secondary antibody for $1 \mathrm{~h}$, rinsed again, and developed using enhanced chemiluminescence (ECL) reagents (Amersham Biosciences, Piscataway, NJ, USA).

\section{Statistics}

All data are expressed as the means \pm SEs of three or more independent experiments. Between-group comparisons were performed using one-way analysis of variance (ANOVA) followed by an appropriate post-hoc test. A value of $p<0.05$ was considered to be statistically significant.

\section{Results}

The ability of oxaliplatin to attenuate growth and induce apoptosis in colon cancer cells depend on the p53 status We herein utilized p53-wild-type and p53-null (gene knockout) HCT116 cells to study whether the effect of oxaliplatin on colon cancer cells is dependent on the functionality of p53. Monitoring of dynamic cell growth by cell impedance measurements, revealed that the presence of p53 does not affect the growth profile of HCT116 cells, since both lines exhibited similar growth rates over $72 \mathrm{~h}$ (Fig. 1a). Oxaliplatin greatly and dose-dependently attenuated the growth of p53-wild-type cells, with an $\mathrm{IC}_{50}$ value of $0.65 \mu \mathrm{M}$ (Fig. 1b). In p53-null cells, in contrast, oxaliplatin did not have any marked inhibitory effect at the tested concentrations; in fact, $1 \mu \mathrm{M}$ oxaliplatin appeared to stimulate cell growth, and the $\mathrm{IC}_{50}$ value was high at $9.67 \mu \mathrm{M}$ (Fig. 1c). This difference in cytotoxicity was also reflected in the apoptotic populations of oxaliplatin-exposed cells: we observed marked increase in the apoptosis of p53-wild-type cells exposed to oxaliplatin in a dose- and time-dependent fashion, whereas minimal (insignificant) apoptosis was induced in p53-null cells exposed to the same doses of oxaliplatin (Fig. 1d). Protein analysis confirmed that the oxaliplatin-induced apoptosis of p53-wild-type cells was associated with up-regulation of the pro-apoptotic proteins, Bak and Bax, down-regulation of the pro-survival factors, Bcl2 and survivin, and the direct cleavage of PARP by caspase 3 (Fig. 1e, left panel). Most recently, the utilization of a single molecule localization microscopy revealed that densely packed Bak clusters on mitochondria are critical for the induction of apoptosis [24]. It is proposed that oxaliplatin-induced Bak up-regulation in p53-wild-type cells observed in this present study may play a necessary role in apoptosis (Fig. 1e, left panel). Consistent with the lack of marked oxaliplatin-induced apoptosis, however, these protein changes were not 

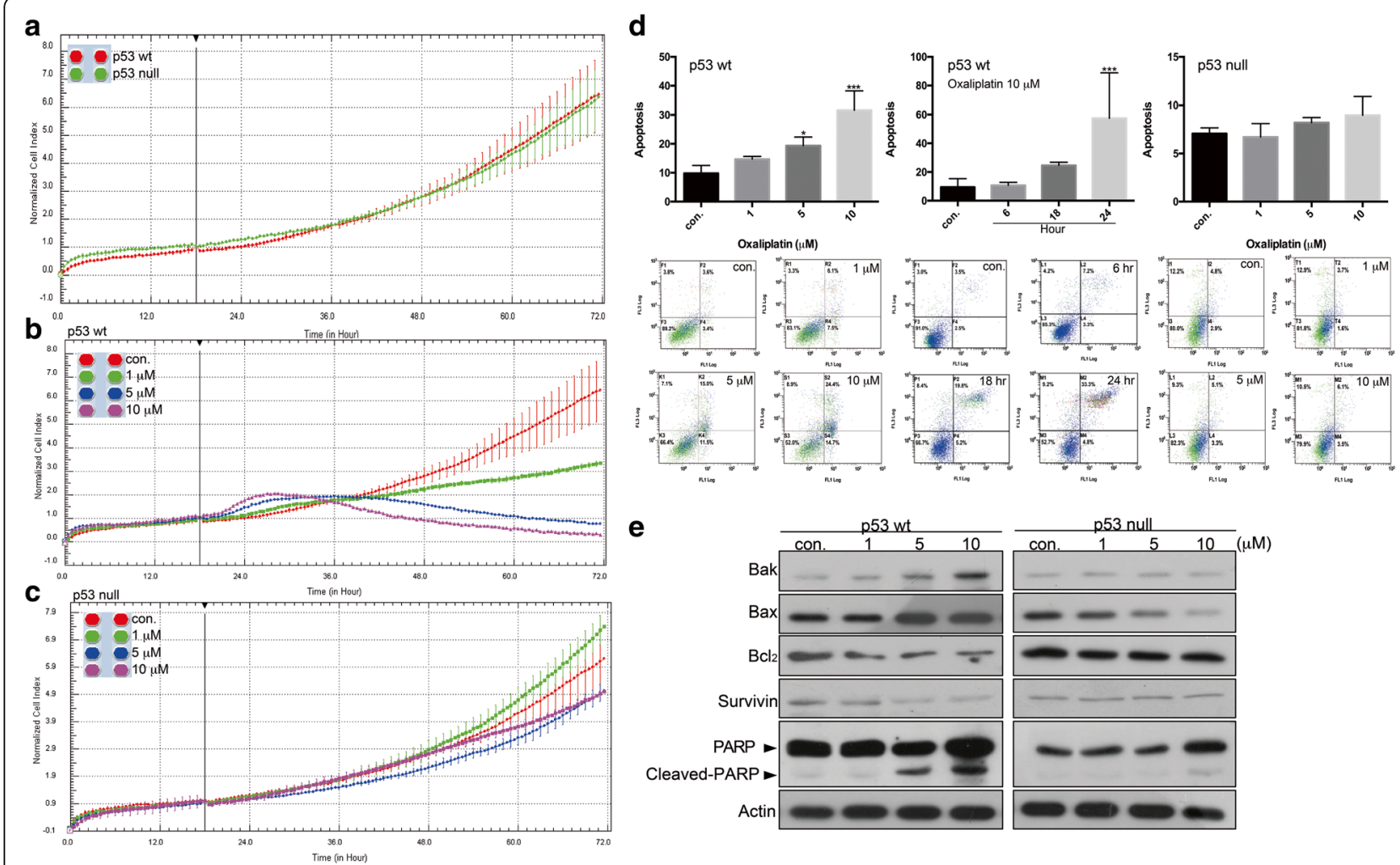

Fig. 1 Oxaliplatin suppresses the growth of HCT116 p53-wild-type cells by inducing apoptosis, but no such effect is seen in p53-null cells. A-C, HCT116 cells were treated without (a) or with (b and $\mathbf{c}$ ) oxaliplatin and cell growth was dynamically monitored using impedance technology. Normalized cell index values measured over $70 \mathrm{~h}$ are shown. $\mathbf{d}$, $\mathrm{HCT} 116$ cells were treated with oxaliplatin or dd $\mathrm{H}_{2} \mathrm{O}$ for different concentrations or time length and the percentage of apoptotic cells was determined by flow cytometry. The results are presented as the percentage of apoptotic cells; the presented values (mean \pm SEs) represent three independent experiments performed in at least triplicate $\left({ }^{*} p<0.05\right.$, ${ }^{* * *} p<0.001$ for cells treated with oxaliplatin vs. controls). Representative images are shown. e, $\mathrm{HCT} 116$ cells were treated with oxaliplatin or ddH $\mathrm{H}_{2} \mathrm{O}$ for $24 \mathrm{~h}$, and cell lysates were separated by SDS-PAGE and analyzed by Western blotting. $\beta$-Actin was used as an internal control. Representative images are shown

observed in p53-null cells treated with oxaliplatin (Fig. 1e, right panel). Interestingly, p53-null cells exposed to oxaliplatin exhibited a Bax down-regulation, associating with little cytotoxicity; such a phenomena is also correlated with colorectal carcinogenesis and drug resistance as reported elsewhere [25].

\section{Oxaliplatin engages with tNOX protein and inhibits its enzymatic activity independent of $\mathrm{p} 53$}

We previously showed that the diverse responsiveness of different stomach cancer lines toward oxaliplatin is reflected in the protein level of tumor-associated NADH oxidase (tNOX) [9]. In the present study, we further investigated whether oxaliplatin engages tNOX to contribute to the induction of the apoptosis in p53-wild-type colon cancer cells. The cellular thermal shift assay (CETSA) is a label-free assay that may be used to study target engagement in cells based on the ability of ligand binding to enhance the stability of target proteins [26, 27]. For CETSA, thermal melting curves are plotted and the melting temperature $\left(T_{\mathrm{m}}\right.$; the temperature at which $50 \%$ of proteins are unfolded and rapidly precipitated by heat) can be derived. We observed an obvious shift in the thermal melting curves in the oxaliplatin-treated lysates of p53-wild-type cells compared to control lysates. The $T_{\mathrm{m}}$ value increased from $48.9{ }^{\circ} \mathrm{C}$ (control) to $54.8{ }^{\circ} \mathrm{C}$ (oxaliplatin-treated), suggesting that oxaliplatin induced thermal stabilization of tNOX using antisera to tNOX (Fig. 2a). In p53-null cells, our results also suggested that oxaliplatin binds to $\mathrm{tNOX}$, with the $T_{\mathrm{m}}$ values increasing from $48.2{ }^{\circ} \mathrm{C}$ (control) to $55.7{ }^{\circ} \mathrm{C}$ (oxaliplatin-treated) (Fig. 2b). The addition of oxaliplatin increased in $T_{\mathrm{m}}$ in both cases, indicating that the drug bound to the tNOX protein. However, the heat-induced unfolding of the thermal melting curves differed between the p53-null and p53-wild-type cells, the latter of which showed a prominent sigmoidal pattern. This suggests that the tNOX-unfolding process might differ in cellular environments with or without p53.

As our CETSA results indicated that oxaliplatin does indeed bind tNOX, we next analyzed whether oxaliplatin binding affects the enzymatic ability of tNOX to convert 

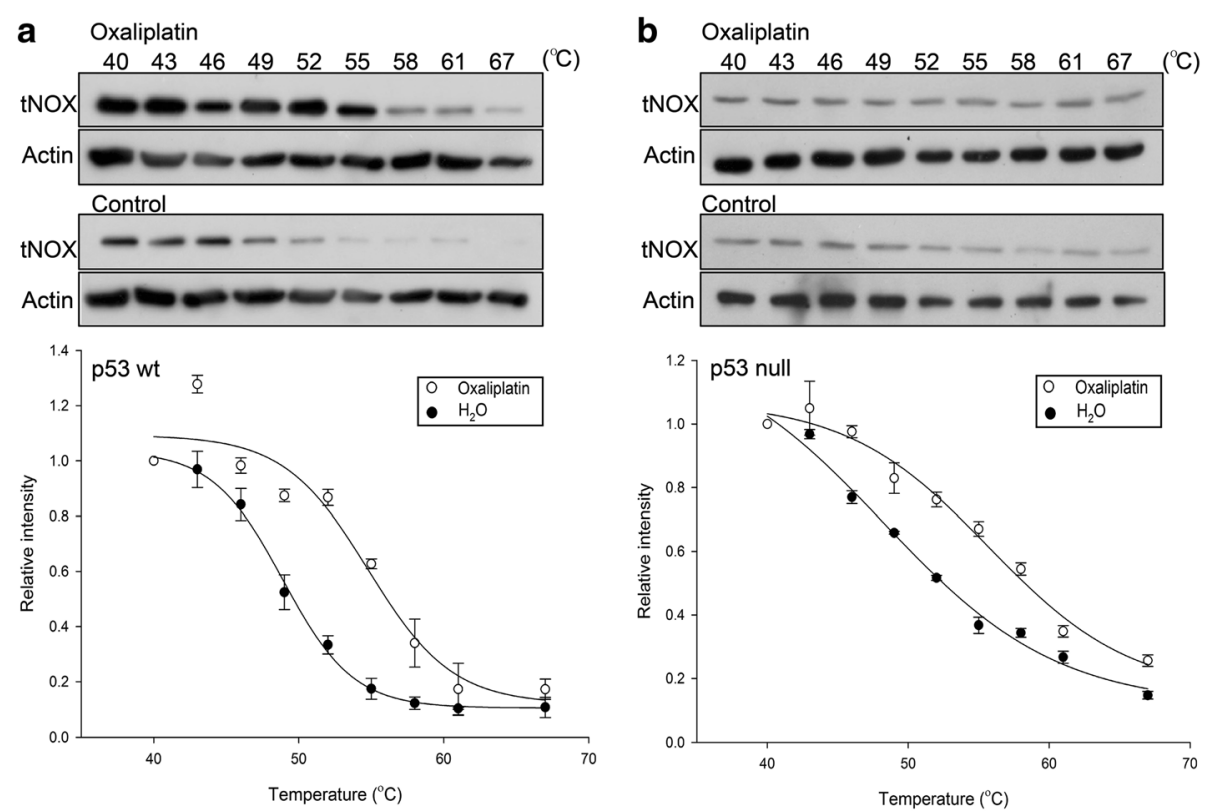

Fig. 2 CETSA-based determination of binding between oxaliplatin and tNOX. A, B, CETSA curves of tNOX in p53-wild-type cells (a) and p53-null cells (b) were determined in the absence and presence of $100 \mu \mathrm{M}$ oxaliplatin, and cell lysates were separated by SDS-PAGE and analyzed by Western blotting. $\beta$-Actin was used as an internal control. Representative images are shown. The band intensities of tNOX were normalized with respect to the intensity at $40^{\circ} \mathrm{C}$. The denaturation midpoints were determined using a standard process

reduced NADH to oxidized $\mathrm{NAD}^{+}[11,12]$. We found that oxaliplatin concentration- and time-dependently decreased the intracellular $\mathrm{NAD}^{+} / \mathrm{NADH}$ ratio in p53-wild-type cells compared to controls, possibly by attenuating tNOX oxidase activity (Fig. 3a). This supports our previous contention that oxaliplatin binds to tNOX and inhibits its enzymatic activity, which in turn reduces the intracellular $\mathrm{NAD}^{+} / \mathrm{NADH}$ ratio [9]. Unexpectedly, a similar pattern was observed in p53-null cells (Fig. 3b). This suggests that the binding of oxaliplatin to tNOX and its effect on enzymatic activity might not be sufficient to explain the different cellular outcomes observed in these two cell lines.

\section{Oxaliplatin-induced apoptosis depends on tNOX down- regulation}

To search for another mechanism that might explain the between-line differences, we next examined tNOX expression in cells treated with oxaliplatin. Western blot analysis showed that oxaliplatin dose-dependently attenuated the level of tNOX in p53-wild-type cells, but had little inhibitory effect in p53-null cells (Fig. 4a and b). Given that tNOX catalyzes the oxidation of NADH to $\mathrm{NAD}^{+}$, and the latter is a cofactor for sirtuin (SIRT1) activity, we next analyzed the impact of oxaliplatin on SIRT1 activity. Interestingly, the protein level of SIRT1 was attenuated and the acetylation of p53 was increased in p53-wild-type cells, suggesting that SIRT1 deacetylase activity was inhibited in these cells (Fig. 4a). This presence of p53 acetylation/activation in wild-type cells is likely to contribute to the ability of oxaliplatin to induce apoptosis (see Fig. 1). In the p53-null cell line, in contrast, oxaliplatin had no inhibitory effect on tNOX expression and SIRT1 expression remained unchanged (Fig. 4b).

The above findings suggest that the down-regulation of tNOX in p53-wild-type cells may explain the differential cellular responses to oxaliplatin in the tested cell lines. Indeed, we obtained comparable results in oxaliplatin-treated AGS (wild-type p53) and TMK-1 (mutant p53) gastric cancer cells (Fig. 4c), and noted that these findings were consistent with the profound apoptotic activity of oxaliplatin in AGS but not TMK-1 cells [9]. Similarly, oxaliplatin induced tNOX down-regulation in SAS tongue squamous carcinoma cells, which carry an E336X mutant (a stop cordon), but exhibiting wild-type p53 function, whereas tNOX expression remained unchanged upon oxaliplatin exposure in HSC-3 oral squamous carcinoma (p53 inactive) cells (Fig. 3c). To test whether the lack of oxaliplatin-induced apoptosis in p53-null/mutated cells is associated with the stability of tNOX, we performed tNOX-specific RNA interference (RNAi) in p53-null HCT116 cells. Indeed, knockdown of tNOX enhanced spontaneous apoptosis in p53-null cells compared to control cells, regardless of oxaliplatin exposure (Fig. 4d). Moreover, tNOX-depleted p53-null cells treated with 5 or $10 \mu \mathrm{M}$ oxaliplatin demonstrated evident induction of apoptosis, whereas the drug was not 

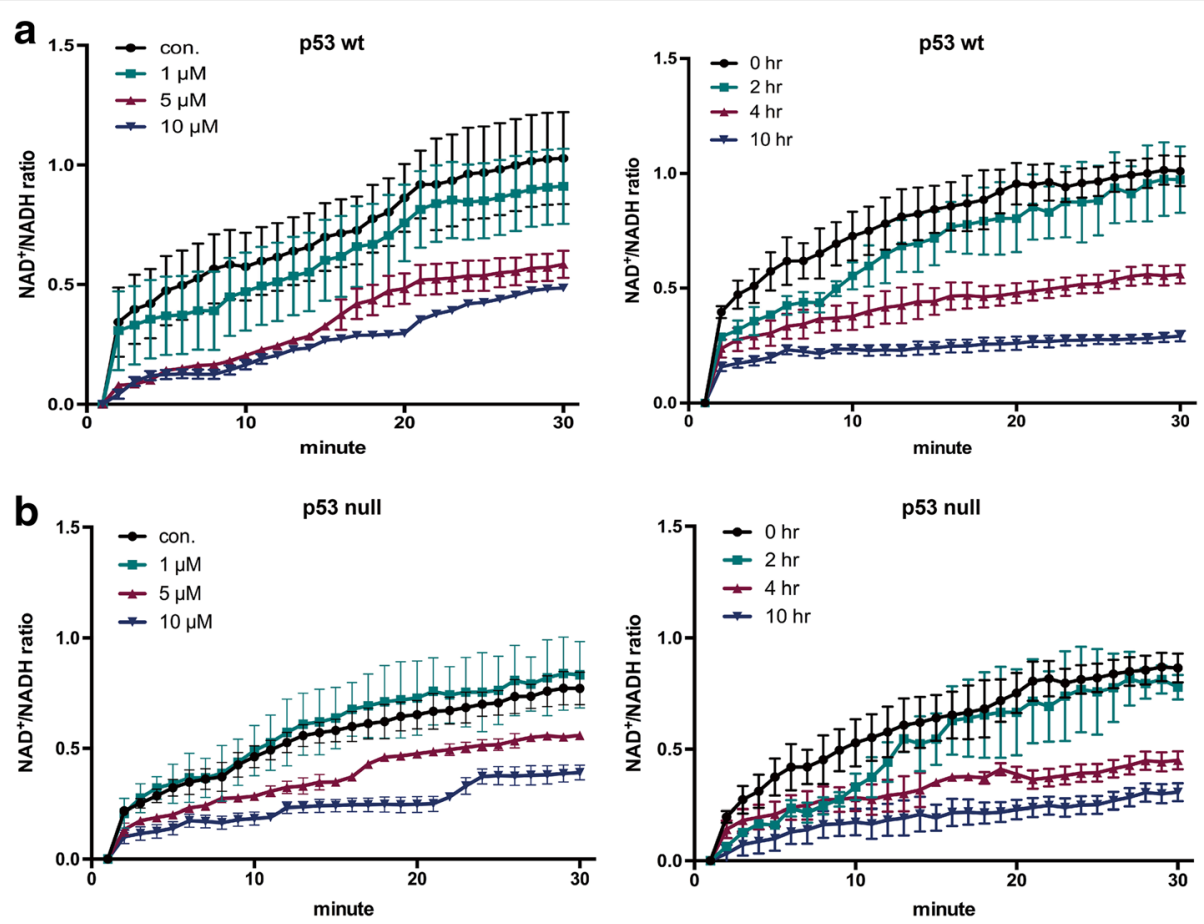

Fig. 3 Oxaliplatin dose- and time-dependently reduces the NAD $/ \mathrm{NADH}$ ratio in HCT116 p53-wild-type (a) and p53-null (b) cells. Cells were treated with $\mathrm{ddH}_{2} \mathrm{O}$ or oxaliplatin, and the $\mathrm{NAD}^{+}$and $\mathrm{NADH}$ levels in cell extracts were quantified based on the optical density at $450 \mathrm{~nm}$, the $\mathrm{NAD}^{+} / \mathrm{NADH}$ ratio was calculated. Values (mean $\pm \mathrm{SEs}$ ) were obtained from at least three independent experiments
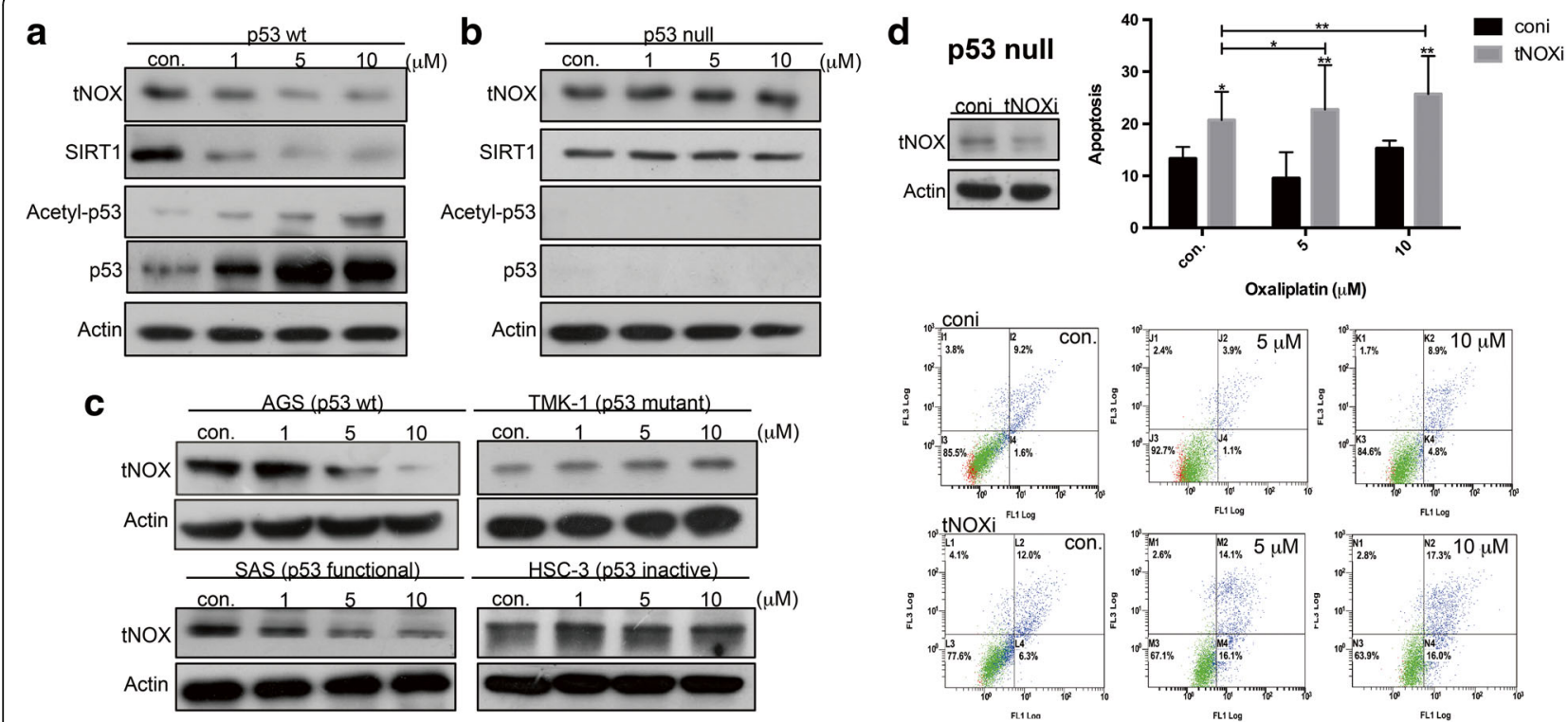

Fig. 4 Oxaliplatin reduces tNOX and SIRT1 expression in p53-wild-type cells but not in p53-null or -mutant cells. a-c, Cell lysates were separated by SDS-PAGE and analyzed by Western blotting. $\beta$-Actin was used as an internal control. Representative images are shown. d, tNOX was knocked down by RNA interference in p53-null cells. The cells were treated with $d \mathrm{dH}_{2} \mathrm{O}$ or oxaliplatin for $24 \mathrm{~h}$, and the percentage of apoptotic cells was determined by flow cytometry. The presented values (mean \pm SEs) represent at least three independent experiments $\left({ }^{*} p<0.05\right.$ or ${ }^{* *} p<0.01$ for tNOX-knockdown cells vs. controls). Representative images are shown 
apoptotic in scrambled siRNA-transfected cells (Fig. 4d). Thus, tNOX appears to be essential for cancer cell survival. These converging lines of evidence reveal that tNOX expression and the ultimate cellular response toward oxaliplatin differ markedly in cells with or without functional p53, further suggesting that targeting of tNOX could be an alternative therapeutic strategy in p53-inactivated cancer scenarios.

\section{Ubiquitination and proteasome degradation contribute to the ability of oxaliplatin to translationally reduce tNOX expression in p53-wild-type cells}

Given that tNOX expression is important for regulating apoptosis and the down-regulation of tNOX depends on $\mathrm{p} 53$ functionality, we examined whether the oxaliplatin-induced down-regulation of tNOX expression in p53-wild-type cells was due to protein degradation. We analyzed protein stability using a cycloheximide-chase assay and found that the half-life of tNOX was markedly decreased in p53-wild-type cells exposed to oxaliplatin for 6 and $9 \mathrm{~h}$ (Fig. 5a). Treatment with the proteasome inhibitor, MG132, significantly improved the stability of tNOX in p53-wild-type cells exposed to oxaliplatin (Fig. 5b). As expected, tNOX stability remained largely unchanged in p53-null cells regardless of oxaliplatin treatment, and MG132 treatment did not alter tNOX stability in these cells (Fig. 5c). These findings indicate that proteasome degradation is indeed involved in the oxaliplatin-induced down-regulation of tNOX in p53-wild-type cells but not in p53-null cells.

\section{ROS-modulated POU3F2 contributes to the oxaliplatin-} induced transcriptional modulation of tNOX expression When we examined the effect of oxaliplatin on the transcriptional expression of tNOX, we found that the drug markedly and concentration-dependently reduced tNOX RNA expression in p53-wild-type cells, whereas that in p53-null cells was gradually enhanced by oxaliplatin as the dose increased, reaching a significant level in cells treated with $10 \mu \mathrm{M}$ oxaliplatin (Fig. 6a). As a previous study showed that the POU domain transcription factor, POU3F2, positively regulates $\mathrm{tNOX}$ expression in gastric cancer cells [28], we examined the potential involvement of POU3F2 in this system. The $1.4 \mathrm{~kb}-5^{\prime}$ promoter region of the tNOX gene was subcloned into the pGL3-basic luciferase reporter vector. We found that co-transfection of HCT116 p53-wild-type cells with the pGL3-1.4 kb promoter and different amounts of a POU3F2-expressing plasmid yielded a concentration-dependent increase in luciferase activity (Fig. 6b), providing a direct link between POU3F2 and tNOX expression. We further found that the oxaliplatin-induced down-regulation of tNOX in p53-wild-type cells was accompanied by attenuated POU3F2 expression; that POU3F2 overexpression up-regulated tNOX expression in these cells; and that oxaliplatin did not induce apoptosis in these POU3F2-overexpressing and tNOX-up-regulated cells (Fig. 6c). In p53-null cells, tNOX expression remained stable following oxaliplatin exposure, but POU3F2 knockdown diminished tNOX expression and was associated with marked apoptosis (Fig. 6d). These findings suggest that POU3F2 is involved in the oxaliplatin-mediated regulation of $\mathrm{tNOX}$ and the subsequent cellular responses.

In view of this significant correlation between POU3F2 and tNOX expression, we investigated the upstream signaling that modulates POU3F2 expression. The POU proteins comprise a large family of homeobox transcription factors binding to an octameric DNA sequence. Interestingly, p53 suppresses oncogenic activation through Brn-3a (POU4F1) [29], while Oct-1 (POU2F1) is known to be down-regulated by oxidative stress [30]. We thus examined whether ROS signaling and p53 are involved in the differential regulation of POU3F2 and subsequent tNOX expression in our system. A profound increase of ROS generation was elicited by $10 \mu \mathrm{M}$ oxaliplatin in p53-wild-type cells, whereas no changes in ROS was
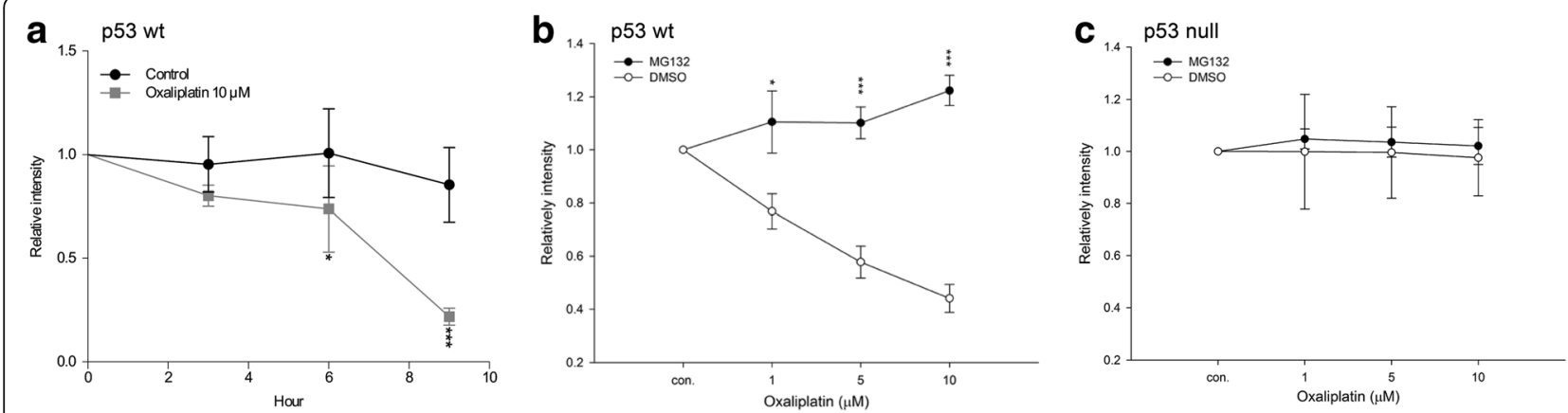

Fig. 5 Oxaliplatin decreases tNOX expression in HCT116 p53-wild-type cells but not in p53-null cells. Cells were pretreated with $50 \mu \mathrm{g} / \mathrm{mL} \mathrm{CHX}$ (a) or MG132 (b, c) for 30 min and exposed to oxaliplatin $(10 \mu \mathrm{M})$ for $24 \mathrm{~h}$, and then analyzed for tNOX expression. The protein intensity of tNOX was determined by densitometric analysis and normalized to the relevant $\beta$-actin value. The presented results represent at least three independent experiments $\left({ }^{*} p<0.05\right.$ or ${ }^{* * *} p<0.001$ for treatments vs. controls) 


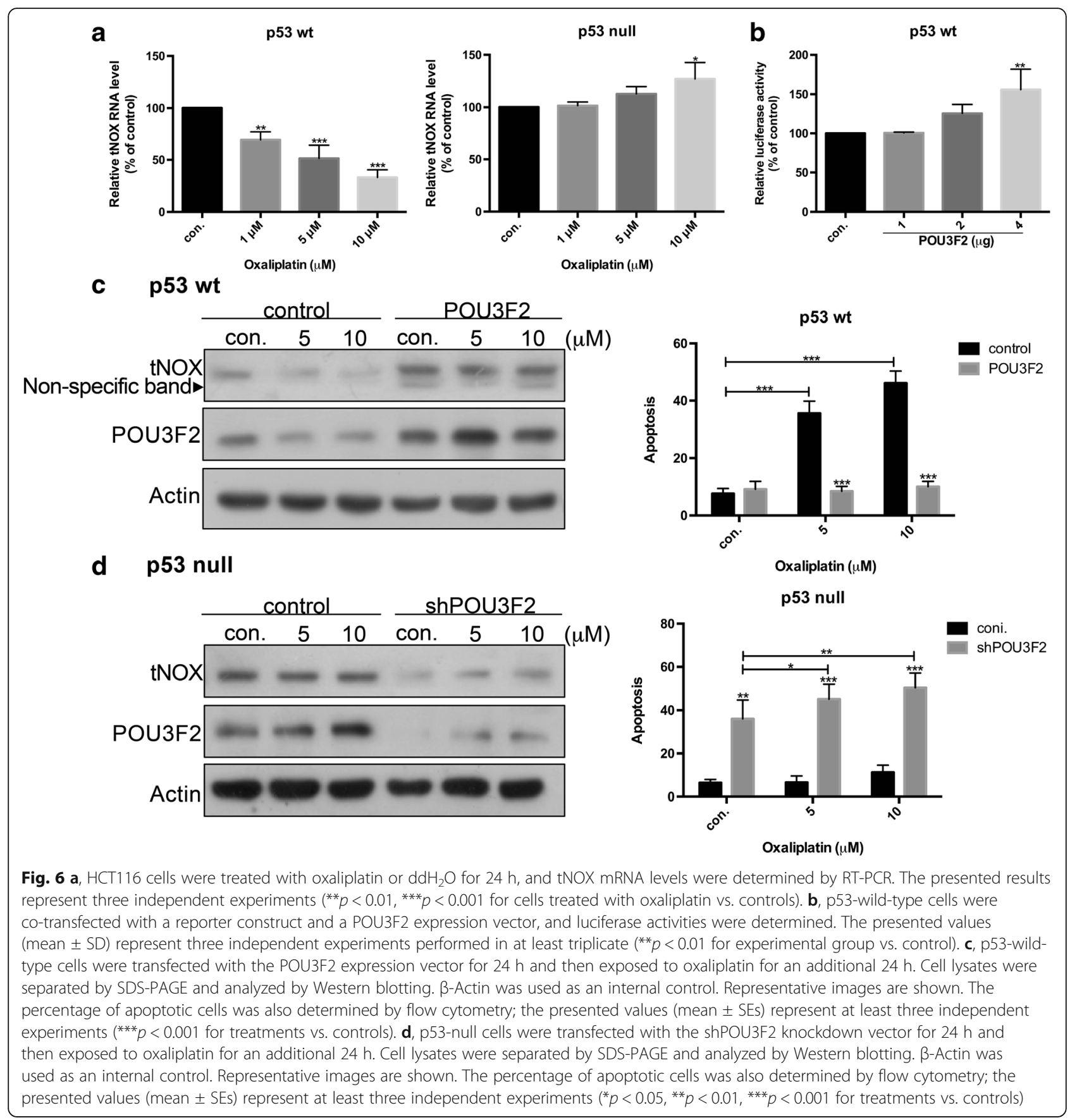

observed in p53-null cells exposed to oxaliplatin (Fig. 7a). We also observed that the expression levels of tNOX and POU3F2 in p53-wild-type cells decreased as the oxaliplatin concentration increased, concurrent with enhancement of p53 phosphorylation, but no such changes was seen in p53-null cells (Fig. 7b). The observed enhancement of p53 phosphorylation prompted us to examine the transcriptional expression of POU3F2 in oxaliplatin-treated cells. Not surprisingly, we observed significant decreases and increases in the transcriptional expression levels of POU3F2 when we treated p53wild-type and -null cells, respectively, with increasing concentrations of oxaliplatin (Fig. 7c). The activation of p53 seemed to correlate with oxidative stress. To examine whether such stress was essential in our system, we used N-acetyl cysteine (NAC) as a ROS scavenger. We found that NAC pre-treatment effectively reduced oxaliplatin-mediated apoptosis in p53-wild-type cells (Fig. 7d). Western blot analysis also revealed that the inhibition of ROS generation reversed the enhancement 


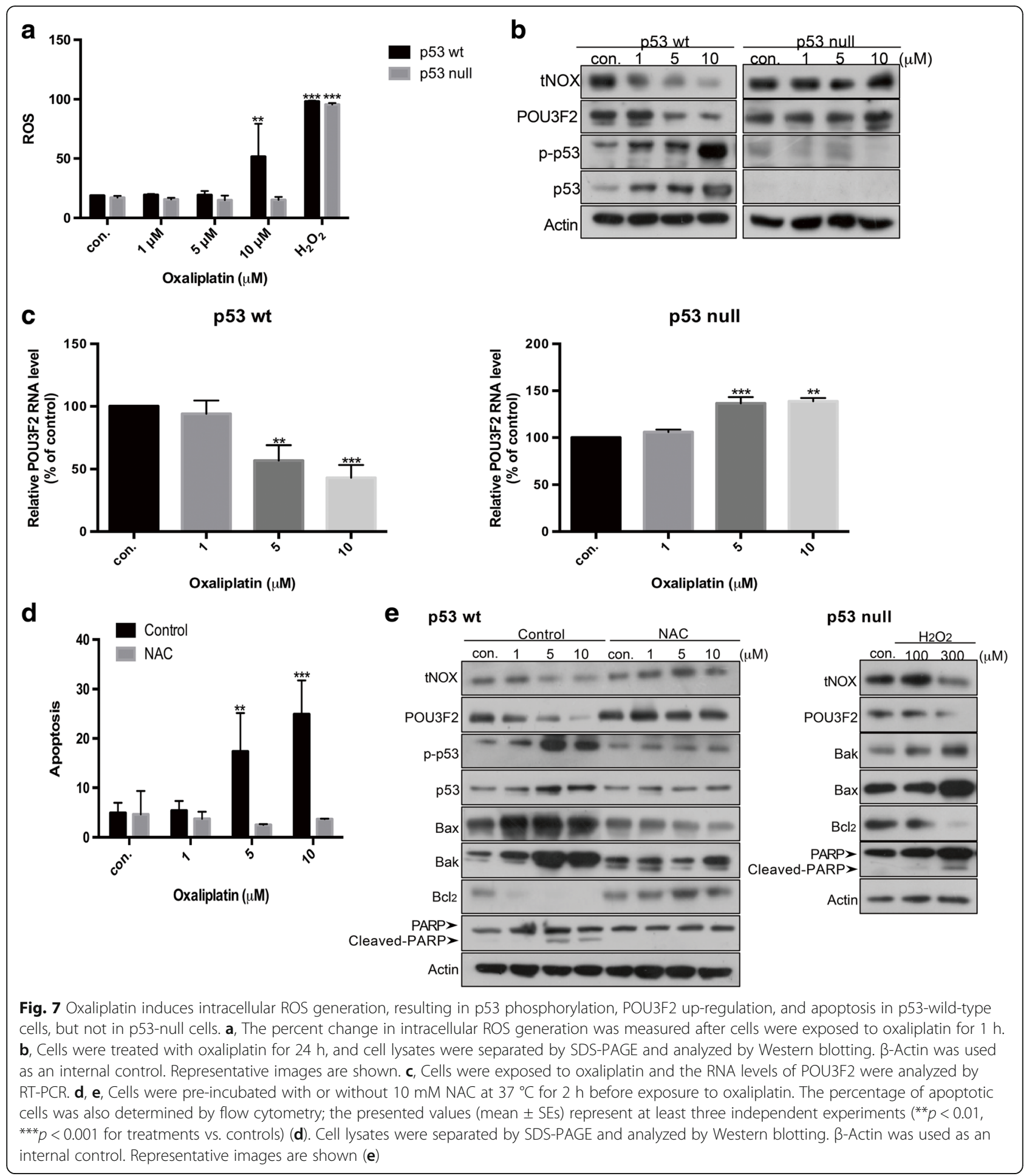

of phosphorylated p53, the down-regulation of POU3F2, tNOX, and $\mathrm{Bcl} 2$, the up-regulation of Bax and Bak, and the direct cleavage of PARP by caspase 3 (Fig. 7e). All of these findings support the notion that oxidative stress plays a vital role in oxaliplatin-mediated tNOX down-regulation and apoptosis in p53-wild-type cells. To validate that p53-null cells are capable of undergoing apoptosis, we used $\mathrm{H}_{2} \mathrm{O}_{2}$ to induce ROS in such cells. Indeed, ROS generation was associated with down-regulation of POU3F2, tNOX, and Bcl2, up-regulation of Bak and Bax, 
and enhanced PARP cleavage in p53-null cells (Fig. 7e), and these findings were accompanied by the induction of apoptosis (Fig. 7a).

Together, our various lines of evidence suggest that oxaliplatin treatment of p53-wild-type cells induced ROS generation, which attenuated POU3F2 and tNOX expression to diminish SIRT1, leading to apoptosis. In p53-null cells, in contrast, oxaliplatin initially inhibited tNOX activity, but the lack of p53 and a slight uptick in ROS generation prompted the up-regulation of POU3F2, leading to the transcriptional enhancement of tNOX expression and subsequent decreases in cellular and oxidative stress. Thus, the globally stable tNOX expression found in p53-null cells ultimately compensates for the inhibitory effect of oxaliplatin on tNOX activity, giving such cells a greater resistance against oxidative stress (Fig. 8).

\section{Discussion}

The ultimate goal of cancer research is to discover ways to conquer cancer cells, such as by making them die selectively. In this study, we investigated the difference in cellular outcomes among oxaliplatin-treated colon cancer cells that differed in their p53 functionality. Importantly, we showed that ROS generation and p53 activation cooperatively act to inhibit tNOX and promote apoptosis in p53-wild-type colon cancer cells. The responsiveness to oxaliplatin was reflected in the ability of oxidative stress to down-regulate POU3F2 and tNOX, which appeared to lessen SIRT1 deacetylase activity, induce p53 activation, and trigger apoptosis in p53-wild-type cells. In contrast, p53-null cells treated with oxaliplatin failed to exhibit

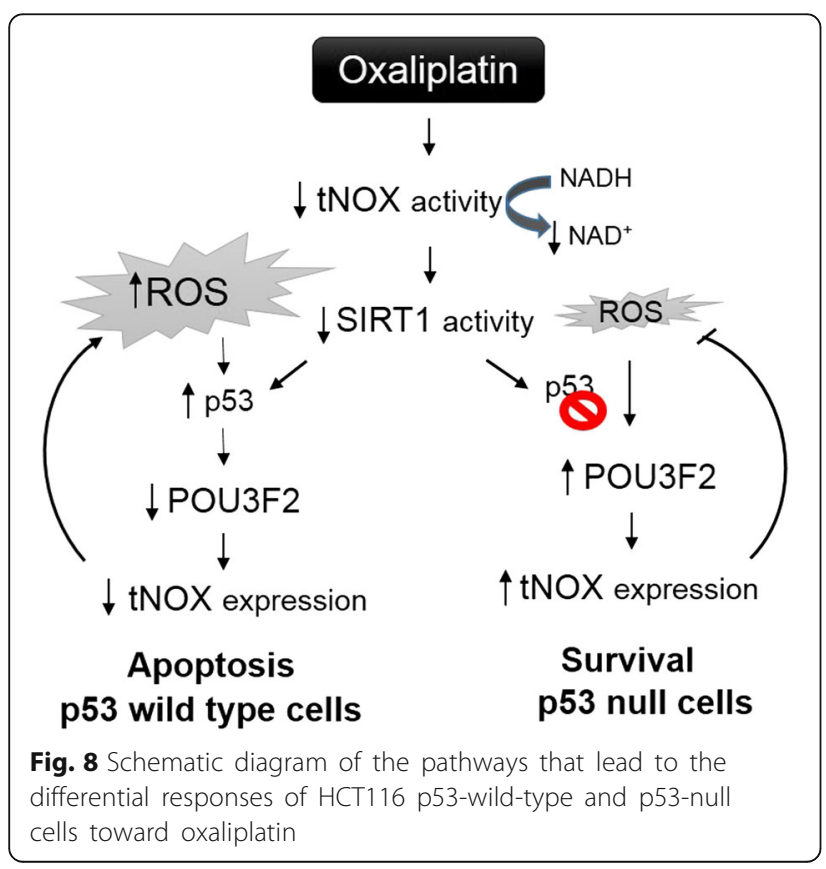

marked ROS generation, perhaps due to the up-regulation of tNOX; their higher oxidative stress tolerance and lack of p53 function led to enhanced cell survival. Notably, the depletion of tNOX could sensitize p53-null cells to both spontaneous and oxaliplatin-induced apoptosis. Our work thus clearly shows a scenario in which targeting of tNOX may be a potential strategy for cancer therapy in a p53-inactivated system.

To the best of our knowledge, this is the first study to suggest that ROS signaling and p53 collaboratively regulate POU3F2 and subsequent tNOX down-regulation. This is a milestone finding for both POU3F2 and tNOX. The molecular cloning of tNOX was initially reported in 2002 [31], but this is the first study to explore the regulation of its expression and that of its transcription factor, POU3F2. Members of the POU domain transcription factor family play essential roles in development and universally share the POU domain, which is a conserved motif that is important for DNA binding. However, each POU factor has its own unique expression pattern and function. Surprisingly, very few studies have focused on the correlation between oxidative stress and various POU factors. The exception is POU2F1, which was demonstrated to act as a sensor and modulate the expression of many target genes in response to cellular stress [32, 33]. Similarly, there is little literature examining the connection between p53 and POU factors. Early studies indicated that anti-oncogenic p53 suppresses the transcriptional expression of anti-apoptotic $\mathrm{Bcl}-2$ and $\mathrm{Bcl}-\mathrm{x}$ through POU4F1 (Brn-3a) [29, 34]. Most recently, p53 silencing was shown to upregulate POU2F1 to enhance CTHRC1 activation and Wnt-PCR signaling, and thus to support the metastasis of cervical cancer [35]. POU3F2, which was examined in the present study, belongs to the class III POU factors; also known as Brn2 or N-Oct3, it has been suggested to promote cell proliferation or even enhance metastatic potential [36-38]. GADD45 was identified as a p53-independent downstream target of POU3F2 in UVB-irradiated melanocytes [39], and we recently reported that POU3F2 is positively correlated with the transcriptional regulation of tNOX, potentially explaining the tumorigenic role of POU3F2 [28]. However, the upstream signaling involved in the regulation of POU3F2 remained largely unknown. In the present study, we dissected the involved pathways and reveal for the first time that ROS is an important upstream signaling component that acts via p53 activation to suppress POU3F2 expression, leading to the down-regulation of tNOX.

Another significant finding of the present work is our decoding of why oxaliplatin triggers differential cellular responses depending on the presence of p53. Oxaliplatin treatment is frequently associated with drug resistance; most such cases have lost p53 functionality, and tackling 
specific proteins, such as Nrf2, FOXM1/Mcl-1, and Oct4, has shown promise for combating this resistance [40-42]. As demonstrated in the present study, POU3F2-induced tNOX up-regulation and a lack of protein degradation contribute to the increased cancer cell survival seen in p53-null cells treated with oxaliplatin. We propose that the stably and enhanced expression of tNOX and consequently augmented ability to oxidize NADH may account for the ability of p53-null cells overcome oxidative stress. The feedback-mediated decrease in ROS generation and the lack of p53 activation lead to the up-regulation of POU3F2 and tNOX and subsequent increase in cancer cell survival. The role of $\mathrm{tNOX}$ in cell survival was further validated by our observation that the apoptotic populations was larger in tNOX-knockdown p53-null cells treated with oxaliplatin compared to the corresponding scrambled siRNA-transfected cells (Fig. 3). Conversely, accumulating data suggest that the cellular $\mathrm{NAD}^{+} / \mathrm{NADH}$ ratio is important for maintaining redox homeostasis, and that its disturbance by an excess of oxidizing or reducing equivalents is associated with stress [43, 44]. Decreased cellular $\mathrm{NAD}^{+}$levels were previously associated with a higher susceptibility to oxidative stress [45]. This notion is also supported by our results demonstrating that, preferentially in p53-wild-type cells, oxaliplatin induced ROS generation and tNOX down-regulation to reduce the level of $\mathrm{NAD}^{+}$, and this virtuous cycle made the cells even more vulnerable to oxidative stress and ultimate apoptosis. Given that p53 is positioned at the frontier between cell survival and apoptosis, it is indeed a great leap forward to consider that targeting tNOX could be a strategy for managing cancer in a p53-defective system.

Target engagement is a key issue in the ability of anticancer drugs to exert the therapeutic effects. It is thus important to identify the functional site of a target protein. Researchers have faced many challenges and limitations in such work, but emerging methods enable target engagements to be determined in living systems [46]. We utilized one such method, the cellular thermal shift assay (CETSA), to show that oxaliplatin directly binds to tNOX and inhibits its oxidase activity. This notion was further supported by our observation that the intracellular $\mathrm{NAD}^{+} / \mathrm{NADH}$ ratio was reduced in oxaliplatin-treated p53-wild-type cells (Fig. 3). This reduction in the $\mathrm{NAD}^{+}$ level impacted SIRT1 activity to activate p53 and apoptosis. This is the first direct evidence that the oxaliplatin acts by engaging tNOX, as the previous studies used indirect methods, such as the investigation of downstream cellular responses to show the interaction. We observed an obvious shift in the thermal melting curves obtained from oxaliplatin-treated lysates of p53-wild-type cells compared to control lysates. Surprisingly, both cell lines exhibited similar increases in $T_{\mathrm{m}}$ following the addition of oxaliplatin. However, the p53-null cells failed to show the prominent sigmoid pattern evidenced by p53-wild-type cells. This indicates that different $\mathrm{tNOX}$ protein processing might occur in the presence or absence of functional p53. This could be an important pathway that is worthy of future investigation.

Taken together, our results show that oxaliplatin mediates differential cellular responses in colon cancer cells depending on their p53 status, and demonstrate that the ROS-p53 axis is important for regulating POU3F2 and its downstream target, tNOX, in this system. Furthermore, we used CETSA to show that tNOX directly engages with oxaliplatin in colon cancer cells lines, explaining its therapeutic action. These findings show that tNOX plays an essential function in the growth regulation and survival of cancer cells, and may provide a rational framework for the further development of tNOX inhibitors as a novel class of anticancer therapeutics.

\section{Conclusions}

In conclusion, we focused on the p53 status and regulation of tNOX expression in HCT116 human colon cancer p53-wild-type and -null cells and show that ROS generation and p53 activation cooperatively act to inhibit POU3F2 and tNOX to promote apoptosis in p53-wild-type cells. In contrast, p53-null cells treated with oxaliplatin fail to exhibit marked ROS generation; their higher oxidative stress tolerance and lack of p53 function lead to enhanced cell survival (Fig. 8). Notably, the depletion of tNOX sensitizes p53-null cells to both spontaneous and oxaliplatin-induced apoptosis. Our work thus clearly shows a scenario in which targeting of $\mathrm{tNOX}$ may be a potential strategy for cancer therapy in a p53-inactivated system.

\section{Abbreviations \\ CETSA: Cellular thermal shift assay; CRC: colorectal cancer; RNAi: RNA interference; ROS: reactive oxygen species; SIRT1: Sirtuin 1; tNOX: tumor- associated NADH oxidase}

\section{Acknowledgements}

The authors thank Dr. Chun-Ying Wu and Dr. Yuen-Chun Li for providing cell lines.

\section{Funding}

Financial support was provided by grants from the Ministry of Sciences and Technology, Taiwan (MOST 106-2320-B-005-008-MY3 to PJC), the Ministry of Health and Welfare, Taiwan (104-13 to TMY), and the Feng-Yuan Hospital,

Taichung, Taiwan (103-004 to SWC)

\section{Availability of data and materials}

The datasets used and analyzed during the present study are available from the corresponding author on reasonable request.

\section{Authors' contributions}

Conceived the study: TMY, SWC, PJC. Wrote the manuscript: PFL, PJC.

Performed the experiments: HYC, Al. Analyzed the data: HYC, Al, TMY, SWC,

PFL, PJC. All authors reviewed and approved the final manuscript.

Ethics approval and consent to participate

Not applicable. 


\section{Consent for publication}

Not applicable.

\section{Competing interests}

The authors declare that they have no competing interests.

\section{Publisher's Note}

Springer Nature remains neutral with regard to jurisdictional claims in published maps and institutional affiliations.

\section{Author details}

'Institute of Biomedical Sciences, National Chung Hsing University, Taichung 40227, Taiwan. ${ }^{2}$ Department of Surgery, Feng-Yuan Hospital, Ministry of Health and Welfare, Taichung 42055, Taiwan. ${ }^{3}$ DDepartment of Food Science and Biotechnology, National Chung Hsing University, 145 Xingda Rd., South Dist, Taichung City 40227, Taiwan. ${ }^{4}$ Graduate Institute of Basic Medicine, China Medical University, Taichung 40402, Taiwan. ${ }^{5}$ Department of Medical Research, China Medical University Hospital, Taichung 40402, Taiwan. ${ }^{6}$ Department of Biotechnology, Asia University, Taichung 41354, Taiwan.

\section{Received: 2 March 2018 Accepted: 10 July 2018}

\section{Published online: 20 July 2018}

\section{References}

1. Siegel RL, Miller KD, Fedewa SA, Ahnen DJ, Meester RGS, Barzi A, Jemal A. Colorectal cancer statistics, 2017. CA Cancer J Clin. 2017;67:177-93.

2. Kelland $L$. The resurgence of platinum-based cancer chemotherapy. Nat Rev Cancer. 2007;7:573-84

3. Hato SV, Khong A, de Vries IJ, Lesterhuis WJ. Molecular pathways: the immunogenic effects of platinum-based chemotherapeutics. Clin Cancer Res. 2014;20:2831-7.

4. Martinez-Balibrea E, Martinez-Cardus A, Gines A, Ruiz de Porras V, Moutinho C, Layos L, Manzano JL, Buges C, Bystrup S, Esteller M, Abad A. Tumorrelated molecular mechanisms of Oxaliplatin resistance. Mol Cancer Ther. 2015;14:1767-76

5. Rakitina TV, Vasilevskaya IA, O'Dwyer PJ. Inhibition of G1/S transition potentiates oxaliplatin-induced cell death in colon cancer cell lines. Biochem Pharmacol. 2007;73:1715-26.

6. McDermott U, Longley DB, Galligan L, Allen W, Wilson T, Johnston PG. Effect of p53 status and STAT1 on chemotherapy-induced, Fas-mediated apoptosis in colorectal cancer. Cancer Res. 2005;65:8951-60.

7. Wiegering A, Matthes N, Muhling B, Koospal M, Quenzer A, Peter S, Germer CT, Linnebacher M, Otto C. Reactivating p53 and inducing tumor apoptosis (RITA) enhances the response of RITA-sensitive colorectal Cancer cells to chemotherapeutic agents 5-fluorouracil and Oxaliplatin. Neoplasia. 2017;19:301-9.

8. Manic S, Gatti L, Carenini N, Fumagalli G, Zunino F, Perego P. Mechanisms controlling sensitivity to platinum complexes: role of p53 and DNA mismatch repair. Curr Cancer Drug Targets. 2003;3:21-9.

9. Chen HY, Cheng HL, Lee YH, Yuan TM, Chen SW, Lin YY, Chueh PJ. Tumorassociated NADH oxidase (tNOX)-NAD+-sirtuin 1 axis contributes to oxaliplatin-induced apoptosis of gastric cancer cells. Oncotarget. 2017

10. Bruno M, Brightman AO, Lawrence J, Werderitsh D, Morré DM, Morré DJ Stimulation of $\mathrm{NADH}$ oxidase activity from rat liver plasma membranes by growth factors and hormones is decreased or absent with hepatoma plasma membranes. Biochem J. 1992;284(Pt 3):625-8.

11. Morré DJ. NADH oxidase: a multifunctional ectoprotein of the eukaryotic cell surface. In: Asard H, Bérczi A, Caubergs R, editors. Plasma membrane redox systems and their role in biological stress and disease. Dordrecht, the Netherlands: Kluwer Academic Publishers; 1998. p. 121-1561.

12. Chueh PJ. Cell membrane redox systems and transformation. Antioxid Redox Signal. 2000;2:177-87.

13. Cheng HL, Lee YH, Yuan TM, Chen SW, Chueh PJ. Update on a tumorassociated NADH oxidase in gastric cancer cell growth. World J Gastroenterol. 2016;22:2900-5.

14. Morre DJ, Chueh PJ, Morre DM. Capsaicin inhibits preferentially the NADH oxidase and growth of transformed cells in culture. Proc Natl Acad Sci U S A. 1995:92:1831-5.

15. Tikhomirov AS, Shchekotikhin AE, Lee YH, Chen YA, Yeh CA, Tatarskiy W Jr, Dezhenkova LG, Glazunova VA, Balzarini J, Shtil AA, Preobrazhenskaya MN, Chueh PJ. Synthesis and characterization of 4,11-Diaminoanthra[2,3-b]furan- 5,10-diones: tumor cell apoptosis through tNOX-modulated NAD(+)/NADH ratio and SIRT1. J Med Chem. 2015:58:9522-34.

16. D.J. Morré, A. Bridge, L.Y. Wu, D.M. Morré, Preferential inhibition by (-)-epigallocatechin-3-gallate of the cell surface NADH oxidase and growth of transformed cells in culture, Biochem Pharmacol, 60 (2000) 937-946.

17. Morré DJ, Caldwell S, Mayorga A, Wu LY, Morré DM. NADH oxidase activity from sera altered by capsaicin is widely distributed among cancer patients. Arch Biochem Biophys. 1997;342:224-30.

18. Morre DJ, Chueh PJ, Yagiz K, Balicki A, Kim C, Morre DM. ECTO-NOX target for the anticancer isoflavene phenoxodiol. Oncol Res. 2007;16:299-312.

19. Mao LC, Wang HM, Lin YY, Chang TK, Hsin YH, Chueh PJ. Stress-induced down-regulation of tumor-associated $\mathrm{NADH}$ oxidase during apoptosis in transformed cells. FEBS Lett. 2008;582:3445-50.

20. Wang HM, Chueh PJ, Chang SP, Yang CL, Shao KN. Effect of Ccapsaicin on tNOX (ENOX2) protein expression in stomach cancer cells. Biofactors. 2008; 34:209-17.

21. H.M. Wang, S.M. Chuang, Y.C. Su, Y.H. Li, P.J. Chueh, Down-regulation of tumor-associated NADH oxidase, tNOX (ENOX2), enhances capsaicininduced inhibition of gastric cancer cell growth, Cell Biochem Biophys, 61 (2011) 355-366.

22. Liu SC, Yang JJ, Shao KN, Chueh PJ. RNA interference targeting tNOX attenuates cell migration via a mechanism that involves membrane association of Rac. Biochem Biophys Res Commun. 2008;365:672-7.

23. Kuo YF, Su YZ, Tseng YH, Wang SY, Wang HM, Chueh PJ. Flavokawain B, a novel chalcone from Alpinia pricei Hayata with potent apoptotic activity: involvement of ROS and GADD153 upstream of mitochondria-dependent apoptosis in HCT116 cells. Free Radic Biol Med. 2010;49:214-26.

24. Nasu Y, Benke A, Arakawa S, Yoshida GJ, Kawamura G, Manley S, Shimizu S, Ozawa T. In situ characterization of Bak clusters responsible for cell death using single molecule localization microscopy. Sci Rep. 2016;6:27505.

25. Manoochehri M, Karbasi A, Bandehpour M, Kazemi B. Down-regulation of BAX gene during carcinogenesis and acquisition of resistance to 5-FU in colorectal cancer. Pathol Oncol Res. 2014;20:301-7.

26. Martinez Molina D, Jafari R, Ignatushchenko M, Seki T, Larsson EA, Dan C, Sreekumar L, Cao Y, Nordlund P. Monitoring drug target engagement in cells and tissues using the cellular thermal shift assay. Science. 2013; 341:84-7.

27. Martinez Molina D, Nordlund P. The cellular thermal shift assay: a novel biophysical assay for in situ drug target engagement and mechanistic biomarker studies. Annu Rev Pharmacol Toxicol. 2016;56:141-61.

28. Chen HY, Lee YH, Chen HY, Yeh CA, Chueh PJ, Lin YM. Capsaicin inhibited aggressive phenotypes through downregulation of tumor-associated $\mathrm{NADH}$ oxidase (tNOX) by POU domain transcription factor POU3F2. Molecules. 2016;21

29. Budhram-Mahadeo V, Morris PJ, Smith MD, Midgley CA, Boxer LM, Latchman DS. p53 suppresses the activation of the Bcl-2 promoter by the Brn-3a POU family transcription factor. J Biol Chem. 1999:274:15237-44.

30. Quan X, Lim SO, Jung G. Reactive oxygen species downregulate catalase expression via methylation of a CpG island in the Oct-1 promoter. FEBS Lett. 2011:585:3436-41

31. Chueh PJ, Kim C, Cho N, Morré DM, Morré DJ. Molecular cloning and characterization of a tumor-associated, growth-related, and time-keeping hydroquinone (NADH) oxidase (tNOX) of the HeLa cell surface. Biochemistry. 2002;41:3732-41.

32. Tantin D, Schild-Poulter C, Wang V, Hache RJ, Sharp PA. The octamer binding transcription factor Oct-1 is a stress sensor. Cancer Res. 2005;65:10750-8.

33. Wang $P$, Jin T. Hydrogen peroxide stimulates nuclear import of the POU homeodomain protein Oct-1 and its repressive effect on the expression of Cdx-2. BMC Cell Biol. 2010;11:56.

34. Sugars KL, Budhram-Mahadeo V, Packham G, Latchman DS. A minimal Bcl-x promoter is activated by Brn-3a and repressed by p53. Nucleic Acids Res. 2001;29:4530-40.

35. Zhang $R$, Lu H, Lyu YY, Yang XM, Zhu LY, Yang GD, Jiang PC, Re $Y$, Song WW, Wang JH, Zhang CC, Gu F, Luo TJ, Wu ZY, Xu CJ. E6/E7-P53-POU2F1CTHRC1 axis promotes cervical cancer metastasis and activates Wnt/PCP pathway. Sci Rep. 2017;7:44744.

36. Goodall J, Martinozzi S, Dexter TJ, Champeval D, Carreira S, Larue L, Goding CR. Brn-2 expression controls melanoma proliferation and is directly regulated by beta-catenin. Mol Cell Biol. 2004;24:2915-22.

37. Goodall J Carreira S, Denat L, Kobi D, Davidson I, Nuciforo P, Sturm RA, Larue L, Goding CR. Brn-2 represses microphthalmia-associated transcription 
factor expression and marks a distinct subpopulation of microphthalmiaassociated transcription factor-negative melanoma cells. Cancer Res. 2008; 68:7788-94.

38. Cook AL, Sturm RA. POU domain transcription factors: BRN2 as a regulator of melanocytic growth and tumourigenesis. Pigm Cell Melanoma R. 2008;21:611-26.

39. Lefort K, Rouault JP, Tondereau L, Magaud JP, Dore JF. The specific activation of gadd45 following UVB radiation requires the POU family gene product N-oct3 in human melanoma cells. Oncogene. 2001;20:7375-85.

40. Tang X, Wang H, Fan L, Wu X, Xin A, Ren H, Wang XJ. Luteolin inhibits Nrf2 leading to negative regulation of the Nrf2/ARE pathway and sensitization of human lung carcinoma A549 cells to therapeutic drugs. Free Radic Biol Med. 2011:50:1599-609.

41. Hu CJ, Wang B, Tang B, Chen BJ, Xiao YF, Qin Y, Yong X, Luo G, Zhang JW, Zhang D, Li S, He FT, Yang SM. The FOXM1-induced resistance to oxaliplatin is partially mediated by its novel target gene Mcl-1 in gastric cancer cells. Bba-Gene Regul Mech. 2015;1849:290-9.

42. Wen KM, Fu ZX, Wu XY, Feng JH, Chen WS, Qian J. Oct-4 is required for an antiapoptotic behavior of chemoresistant colorectal cancer cells enriched for cancer stem cells: effects associated with STAT3/Survivin. Cancer Lett. 2013;333:56-65.

43. Xiao W, Wang RS, Handy DE, Loscalzo J. NAD(H) and NADP(H) redox couples and cellular energy metabolism. Antioxid Redox Signal. 2018:28:251-72

44. Handy DE, Loscalzo J. Responses to reductive stress in the cardiovascular system. Free Radic Biol Med. 2017:109:114-24.

45. Hu Y, Wang H, Wang Q, Deng H. Overexpression of CD38 decreases cellular NAD levels and alters the expression of proteins involved in energy metabolism and antioxidant defense. J Proteome Res. 2014;13:786-95.

46. Simon GM, Niphakis MJ, Cravatt BF. Determining target engagement in living systems. Nat Chem Biol. 2013;9:200-5.

Ready to submit your research? Choose BMC and benefit from:

- fast, convenient online submission

- thorough peer review by experienced researchers in your field

- rapid publication on acceptance

- support for research data, including large and complex data types

- gold Open Access which fosters wider collaboration and increased citations

- maximum visibility for your research: over $100 \mathrm{M}$ website views per year

At $\mathrm{BMC}$, research is always in progress.

Learn more biomedcentral.com/submissions 